\title{
Emergência de sementes de soja com diferentes porcentagens de infestação de mancha púrpura
}

\author{
Francisco Mickael de Medeiros Câmara ${ }^{1 *}$, Fiorita Faria Monteiro ${ }^{1}$, Denis Henrique Silva Nadaleti ${ }^{1}$, Renata \\ Amato Moreira ${ }^{1}$, Harianna Paula Alves de Azevedo ${ }^{1}$, Adriano Teodoro Bruzi ${ }^{1}$
}

\begin{abstract}
RESUMO: A soja apresenta susceptibilidade às diversas doenças em campo, como é o caso da mancha púrpura em sementes causada pelo fungo Cercospora Kikuchii, sendo responsável por severas reduções no rendimento e na qualidade de sementes. Objetivou-se com este trabalho avaliar a emergência e o vigor de sementes de soja (RK7813) em lotes com diferentes porcentagens de infestação de mancha púrpura. Foi utilizado delineamento em blocos casualizados com cinco tratamentos $(0 \%, 25 \%, 50 \%, 75 \%$ e $100 \%$ de mancha púrpura nas sementes) e quatro repetições. As variáveis estudadas foram: a porcentagem de emergência (\%E), a velocidade de emergência (VE), o índice de velocidade de emergência (IVE), a matéria fresca (MV) e a matéria seca (MS) das plântulas. As sementes de soja não foram afetadas pela infestação do Cercospora kikuchii com relação à germinação e acúmulo de matéria fresca e seca. Assim sendo, são necessários estudos ainda mais aprofundados sobre a interação deste patógeno com a cultura, analisar por um maior período para que ocorra uma abordagem mais conclusiva sobre seu efeito nas sementes.
\end{abstract}

Palavras-chave: Cercospora kikuchii; teste de vigor, germinação.

\section{Emergence of soybean seeds with different percentages of purple spot infestation}

\begin{abstract}
Soybean has susceptibility to several diseases in the field, such as the purple seed stain caused by Cercospora Kikuchii, responsible for severe reductions in the yield and quality of seeds. The aim of this study was to evaluate the emergence and soybean seed vigor (RK7813) in batches with different percentages of purple stain infestation. It was used a randomized block design with five treatments $(0 \%, 25 \%, 50 \%, 75 \%$ and $100 \%$ purple stain on the seeds) and four replications. The variables studied were: emergency percentage (\%E), emergency speed (ES), emergency velocity index (EVI), the fresh matter (FM) and dry matter (DM) of seedlings. The soybean seeds are not affected by Cercospora kikuchii infestation in relation to germination and accumulation of fresh and dry matter. Therefore, further studies on the interaction of this pathogen with the crop are required, and a longer period of time should be considered for a more conclusive approach to its effect on the seeds.
\end{abstract}

Key-words: Cercospora kikuchii; vigor, germination.

\section{INTRODUÇÃO}

A soja (Glycine Max L. Merril) é a mais importante oleaginosa produzida mundialmente, tendo como maior produtor os Estados Unidos e o Brasil como segundo em produção e primeiro em exportação (KOHLHEPP, 2010). É amplamente utilizada na produção de ração animal, produção de óleo e outros subprodutos, além do seu consumo in natura que tem se expandido nas últimas décadas (ARAÚJO, 2009).

Segundo Ávila, Albrecht (2010), a importância da soja também vem sendo enfatizada como alternativa na prevenção de doenças e na alimentação humana, podendo ser transformada em diversos alimentos proteicos tais como, farinha, leite, proteína texturizada e creme e ainda para uso industrial na fabricação de derivados não tradicionais, como biodiesel, tintas e vernizes, entre outros

Em função do custo de produção da cultura da soja, é necessário planejamento e cuidados desde o plantio ao armazenamento para manter rentável ao produtor o cultivo desta oleaginosa. A obtenção de elevados rendimentos no campo se inicia com a escolha da cultivar adaptada e sementes de qualidade.

A qualidade de sementes é a associação de atributos físicos, genéticos, fisiológicos e sanitários. Tal qualidade deve ser observada no processo de produção, no campo e nas usinas de beneficiamento (SILVA et al., 2008).

A mancha púrpura ou crestamento foliar de Cercospora é causado pela Cercospora kikuchii, sendo uma doença significativa da soja, causando perdas média estimadas de 112.445 toneladas anuais nos Estados Unidos de 1996 a 2013 (WRATHER; KOENNING, 2009; PRICE et al., 2015).

A soja na maioria das regiões produtoras é cultivada sob condições que favorecem a sobrevivência de agentes patogênicos e o desenvolvimento de doenças. As perdas no seu rendimento em função das doenças variam devido ao clima na maioria dos países (KOENNING; WRATHER, 2010).

Recebido em 20/02/2018; Aceito para publicação em 30/04/2019

${ }^{1}$ Universidade Federal de Lavras

*email: mickaelmedeiros@ hotmail.com 
Em relação à qualidade sanitária, a soja apresenta susceptibilidade a diversas doenças em campo, como é o caso da mancha púrpura em sementes de soja causado pelo fungo Cercospora kikuchii, que é responsável por severas reduções no rendimento e na qualidade das sementes.

A mancha púrpura ou crestamento foliar de Cercospora são conhecidos como doenças de final de ciclo (DFC) por ocorrerem com maior severidade na fase final de enchimento de grãos na soja. Entre as principais medidas de controle dessas doenças está a utilização de sementes sadias, o tratamento de sementes, a incorporação de restos de culturais, a aplicação de fungicidas entre o florescimento e enchimento de grãos e a rotação de cultura com espécies não suscetíveis (KLINGELFUSS, YORINORI, 2001).

Após o ponto de maturidade fisiológica, ou no armazenamento, a presença de micro-organismos patogênicos reduz o potencial fisiológico e a qualidade sanitária das sementes em maior velocidade (BARBOSA et al., 2013).

Para se avaliar a qualidade fisiológica das sementes a maneira oficial é pelo teste de germinação que fornece o potencial de germinação do lote após a sua semeadura, quando conduzido sob condições ótimas de ambiente. Entretanto, em razão de suas limitações, principalmente quanto à menor sensibilidade para a diferenciação da qualidade e à frequente discrepância dos resultados, com a emergência das plântulas em campo recomenda-se também a avaliação da qualidade fisiológica de sementes por meio de testes de vigor (OHLSON, 2010).

Nesse sentido, o teste de emergência em campo auxilia na estimação do vigor das sementes. Quando associado à presença de patógenos, o teste de vigor é ainda mais sensível para identificar diferenças sutis no potencial fisiológico, entre lotes com germinação aceitável (RAMOS et al., 2014).

Devido a isso, objetivou-se com este trabalho avaliar a emergência e o vigor de sementes de soja (RK7813) em lotes com diferentes porcentagens de infestação de Mancha Púrpura.

\section{MATERIAL E MÉTODOS}

$\mathrm{O}$ experimento foi realizado em canteiros ao ar livre no setor de Sementes do Departamento de Agricultura da Universidade Federal de LavrasUFLA, (Latitude: -21.226632, Longitude: 44.972115, altitude: 912m). A cidade de Lavras segundo a classificação de Köppen caracteriza-se como clima subtropical/clima tropical de altitude (SÁ JÚNIOR, 2007).
Foram utilizadas no experimento sementes de soja da cultivar RK7813 (Riber sementes ${ }^{\circledR}$ ). Semeadas na primeira quinzena de dezembro de 2015, as sementes foram inoculadas com Bradyrhizobium japonicum para proporcionar uma melhor fixação de nitrogênio. A adubação consistiu de 400kg.ha ${ }^{-1}$ de 02-30-20 (NPK) após prévia análise do solo. Foi realizado o controle de plantas daninhas, pragas e doenças à medida que se fez necessário.

A colheita das sementes em campo foi realizada no estádio R8, segundo a escala de Fehr et al. (1971). Após a debulha, as sementes foram separadas das impurezas, com o auxílio de peneiras, sendo acondicionadas em sacos de papel. As sementes com teor de umidade elevado foram expostas ao sol até atingirem o teor de 13\%, adequado para o armazenamento.

Os tratamentos foram constituídos pelas diferentes porcentagens $(0 \%, 25 \%, 50 \%, 75 \%$ e $100 \%$ ) de mancha púrpura nas sementes. As porcentagens foram determinadas visualmente, separando as sementes com presença de mancha púrpura das sementes sadias, para distribuí-las proporcionalmente em seus respectivos tratamentos.

O plantio foi realizado manualmente no começo do mês de junho de 2016, em canteiro ao ar livre. As sementes foram distribuídas aleatoriamente de acordo com o tratamento e suas repetições em linhas com 50 furos. Nas laterais continham 2 linhas de bordaduras, para que o experimento não sofresse interferência. A profundidade de plantio foi de 2,5 $\mathrm{cm}$ e o espaçamento entre linhas foi de $5 \mathrm{~cm}$.

Os tratamentos foram distribuídos em delineamento em blocos casualizados (DBC), com cinco tratamentos e quatro repetições e cada parcela foi constituída de cinquenta sementes. As variáveis estudadas foram: \% de emergência, velocidade de emergência (V.E), índice de velocidade de emergência (IVE), massa verde (MV) e massa seca (MS) das plântulas.

Foi realizado o teste de emergência em canteiro, utilizando-se de leituras das plântulas emergidas diariamente até a estabilização. Para os resultados obtidos foi aplicada a fórmula de Magüire (1962) para o I.V.E:

I.V.E. $=(\mathrm{G} 1 / \mathrm{N} 1)+(\mathrm{G} 2 / \mathrm{N} 2)+\ldots+(\mathrm{Gn} / \mathrm{Nn})$, onde: I.V.E. = índice de velocidade de emergência; $\mathrm{G}=$ número de plântulas normais computadas nas contagens; $\mathrm{N}=$ número de dias da semeadura à $1 \mathrm{a}$, 2a ... enésima avaliação.

E para a velocidade de emergência (V.E.), utilizando-se a fórmula proposta por Edmond \& Drapala (1958):

V.E. $=[(\mathrm{N} 1 * \mathrm{G} 1)+(\mathrm{N} 2 * \mathrm{G} 2)+\ldots+(\mathrm{Nn} * \mathrm{Gn})] /$ $(\mathrm{G} 1+\mathrm{G} 2+\ldots+\mathrm{Gn})$, onde: V.E. $=$ velocidade de emergência (dias); $G$ = número de plântulas 
emergidas observadas em cada contagem; $\mathrm{N}=$ número de dias da semeadura a cada contagem.

Ao atingirem a estabilização da emergência, 10 plantas aleatórias por repetição, sendo 40 de cada tratamento foram seccionadas na altura do colo e as partes aéreas foram colocadas em saquinhos de pão e pesadas em balança de precisão para obtenção da massa verde, posteriormente foram colocadas em estufa com circulação forçada de ar a $60{ }^{\circ} \mathrm{C}$, para secagem até atingirem peso constante, segundo Rosolem et al. (1994), para a obtenção da massa seca.

1 )

Tabela1. Médias do índice de velocidade de emergência (IVE), velocidade de emergência (VE), matéria fresca (MF), matéria seca (MS) e porcentagem de emergência (\%EM) de plântulas de soja em função de diferentes porcentagens de infestação de mancha púrpura.

\begin{tabular}{cccccc}
\hline \multirow{2}{*}{ TRATAMENTOS } & \multicolumn{5}{c}{ VARIÁVEIS ANALISADAS } \\
\cline { 2 - 6 } & IVE & VE (dias) & MF $(\mathrm{g})$ & MS $(\mathrm{g})$ & $\%$ EM \\
\hline $0 \%$ & $17,17 \mathrm{~b}$ & $11,49 \mathrm{a}$ & $9,76 \mathrm{~b}$ & $4,45 \mathrm{~b}$ & $2,24 \mathrm{~b}$ \\
$25 \%$ & $12,84 \mathrm{~b}$ & $11,63 \mathrm{a}$ & $9,74 \mathrm{~b}$ & $4,61 \mathrm{ab}$ & $2,36 \mathrm{~b}$ \\
$50 \%$ & $12,97 \mathrm{~b}$ & $14,82 \mathrm{a}$ & $10,91 \mathrm{ab}$ & $4,66 \mathrm{ab}$ & $2,48 \mathrm{ab}$ \\
$75 \%$ & $38,11 \mathrm{a}$ & $9,18 \mathrm{a}$ & $11,10 \mathrm{ab}$ & $4,68 \mathrm{ab}$ & $2,83 \mathrm{a}$ \\
$100 \%$ & $38,66 \mathrm{a}$ & $9,62 \mathrm{a}$ & $12,30^{\mathrm{a}}$ & $4,92 \mathrm{a}$ & $2,83 \mathrm{a}$ \\
\hline DMS & 14,27 & 6,85 & 0,55 & 0,10 & 0,44 \\
\hline
\end{tabular}

* Médias seguidas pela mesma letra, nas colunas, não diferem entre si pelo teste de Tukey ao nível de 5\% de probabilidade.

Os resultados do teste de emergência são de grande valia para a comparação entre lotes de sementes, para fins de comercialização, e para cálculo da densidade de semeadura. Venturoso et al. (2008), obtiveram resultados diferentes onde trabalhando com diferentes classes de infestação por mancha púrpura sobre o vigor de sementes de soja, observaram que todas as cultivares na ausência de mancha púrpura apresentaram emergência superior quando comparada àquelas infestadas, independente dos níveis de infestação.

Houve um aumento da MF e MS com o aumento da porcentagem de infestação de mancha púrpura nas sementes, porém a variação da MS foi menor. As sementes com 100, 75 e $50 \%$ apresentaram as maiores médias para essas variáveis, na qual obtevese $12,30,11,10$ e 10,91 g para matéria fresca e 4,92, 4,68 e 4,66 g para MS respectivamente (Tabela 1).

As sementes com 100 e $75 \%$ de infestação apresentaram médias iguais para a porcentagem de emergência de plântulas 2,83 $(72,67 \%)$, porém superiores as sementes com 25 e $0 \%$ de infestação (Tabela 1).

Apesar das sementes com maiores porcentagens de infestação apresentarem melhores resultados para teste de emergência e acumulo de matéria fresca e seca, isso pode ter ocorrido em função do nível de colonização de cada semente não ter sido suficiente para diminuir o vigor de emergência além das

Após a coleta dos dados, foi realizada a análise de variância e posteriormente um teste de médias. Para as comparações de médias, foi utilizado o teste de Scott Knott a 5\% de probabilidade. As análises estatísticas foram realizadas por meio do programa Sisvar (FERREIRA, 2011).

\section{RESULTADOS E DISCUSSÃO}

As sementes com 100 e $75 \%$ de infestação de mancha púrpura apresentaram maiores médias de IVE, com 38,66 e 38,11 respectivamente (TABELA ). 
mais eficientemente tentando desenvolver-se o mais rápido possível e resistir ao ataque do patógeno.

Segundo Fernandes et al. (2009), as plantas apresentam resposta hipersensitiva ou reação de hipersensibilidade, na qual é considerada como um dos principais eventos da resposta de defesa da planta contra o ataque de patógenos, se caracterizando por ser uma resposta rápida e localizada, ou seja, que ocorre no sítio de infecção do patógeno. Ela se constitui na primeira etapa da resposta de defesa da planta, sendo seguida de outras alterações, quer seja no sítio de infecção ou em toda a planta. Estas alterações podem significar o estabelecimento de interações compatíveis ou incompatíveis entre o patógeno e o hospedeiro.

\section{CONCLUSÃO}

As sementes de soja não foram afetadas pela infestação do Cercospora kikuchii com relação à germinação e acúmulo de matéria fresca e seca. Assim sendo, são necessários estudos ainda mais aprofundados sobre a interação deste patógeno com a cultura, analisar por um maior período para que ocorra uma abordagem mais conclusiva sobre seu efeito nas sementes.

\section{REFERÊNCIAS}

ARAÚJO, M. M. Caracterização e seleção de linhagens de soja resistentes ou tolerantes à ferrugem asiática., 2009. 77p. Dissertação (Mestrado em Genética e Melhoramento de Plantas). Universidade de São Paulo: Escola Siperior de Agricultura "Luiz de Queiroz", Piracicaba.

ÁVILA, M. R.; ALBRECHT, L. P. Isoflavonas e a qualidade das sementes de soja. Informativo Abrates, Londrina, v.20, n.1, p.15-29, 2010.

BARBOSA, R. M.; SANTOS, J. F. dos; LOPES, M. de M.; PANIZZI, R. de C.; VIEIRA, R. D. Chemical control of pathogens and the physiological performance of peanut seeds. International Journal of Food, Agriculture and Environment, Helsinki, v.11, n.2, p. 322-326, 2013. http://hdl.handle.net/11449/76039.

CASA, R. T.; REIS, E. M.; MEDEIROS, C. A.; MOURA, B. Efeito do tratamento de sementes de milho com fungicida, na proteção de fungos do solo no Rio Grande do sul. Fitopatologia Brasileira, Brasília, v.20, n.4, p. 633-638, 1995.

EDMOND, J. B.; DRAPALA, W. J. The effects of temperature, sand and soil, and acetone on germination of okra seeds. Proceedings of American Society of Horticultural Science, Alexandria, v.71, n.2, p.428-434, 1958.

FEHR, W. R., CAVINESS, R. E., BURMOOD, D. T., PENNINETON, J. S. Stage of development descriptions for soybeans, Glycine $\max$ L. Merrill. Crop Science, Madison, v. 11, n. 6, p. 929-931, 1971.

FERNANDES, C. F.; VIEIRA JÚNIOR, J. R.; SILVA, D. S. G.; REIS, N. D.; ANTUNES JÚNIOR, H. Mecanismos de defesa de plantas contra ataque de agentes fitopatogênicos. EMBRAPA, documentos 133,

Rondônia, 2009.

FERREIRA, D. F. Sisvar: A computer statistical analysis system. Ciência e Agrotecnologia, Lavras, v.35, n.6, p.1039-1042, 2011. http://dx.doi.org/10.1590/S141370542011000600001 .

SÁ JÚNIOR, A. de. Aplicação da classificação de Köppen para o zoneamento climático do estado de Minas Gerais. 2009. 101 p. Dissertação (Mestrado em Engenharia Agrícola/Engenharia de Água e Solo) Universidade Federal de Lavras, Lavras.

KLINGELFUSS, L. H.; YORINORI, J. T. Infecção latente de Colletotrichum truncatum e Cercospora Kikuchii e efeito de fungicidas sobre doenças de final de ciclo da soja. Summa Phytophatologica, Botucatu, v. 26, n. 1 , p. 356-361, 2001. http://dx.doi.org/10.1590/S010041582001000200007.

KOENNING, S. R.; WRATHER, J. A. Suppression of Soybean Yield Potential in the Continental United States by Plant Diseases from 2006 to 2009. Plant Health Progress, Saint Paul, v.11, n.1, p.1-6. 2010.

KOHLHEPP, G. Análise da situação da produção de etanol e biodiesel no Brasil. Estudos avançados. São Paulo, v. 24, n. 68, p. 223-253, 2010. http://dx.doi.org/10.1590/S0103-40142010000100017.

LUCCA FILHO, O. A.; CASELA, C. R. Avaliação dos efeitos da mancha púrpura (Cercospora kikuchii) em soja. In: CONGRESSO BRASILEIRO DE SEMENTES, 3., 1983 Campinas. Resumos...Brasília: ABRATES, 1983. p.75.

MAGÜIRE, J. D. Seeds of germination and selection and evaluation for seedling emergence and vigor. Crop Science, Madison, v. 2, n. 2, p. 176-177, 1962.

OHLSON, O. C.; KRZYZANOWSKI, F. C.; CAIEIRO, J.T.; PANOBIANCO, M. Teste de envelhecimento acelerado em sementes trigo. Revista Brasileira de Sementes, Londrina, 32:118-124. 2010. http://dx.doi.org/10.1590/S0101-31222010000400013.

PRICE, P. P.; PURVIS, M. A.; CAI, G.; PADGETT, G. B.; ROBERTSON, C. L.; SCHNEIDER, R. W.; ALBU, S. Fungicide resistance in Cercospora kikuchii, asoybean pathogen. Plant Disease, Saint Paul, v. 99, n. 11, p. 15961603, 2015. https://doi.org/10.1094/PDIS-07-14-0782RE. 
ROSOLEM, C. A.; ALMEIDA, A. C. S.; SACRAMENTO, L. V. S. Sistema radicular e nutrição da soja em função da compactação do solo. Bragantia. Instituto Agronômico de Campinas, v. 53, n. 2, p. 259266, 1994.

RAMOS, D. P.; BARBOSA, R. M.; VIEIRA, B. G. T. L.; PANIZZI, R. C.; VIEIRA, R. D. Infecção por fusarium graminearum e Fusarium verticillioides em sementes de milho. Pesquisa Agropecuária Tropical, Goiânia, v.44, n.1, p. 24-31, 2014.

SILVA, N. O.; RAMALHO, M. A. P.; BRUZI, A. T.; VON PINHO, E. V. R. Genetic control of traits associated with maize seed quality population. Maydica, Sant'Angelo Lodigiano, v. 53, n. 1, p. 55- 62, 2008.

Toledo, M. Z.; Fonseca, N. R.; César, M. L.; Soratto, R. P.; Cavariani, C.; Crusciol, C. A. C. Qualidade fisiológica e armazenamento de sementes de feijão em função da aplicação tardia de nitrogênio em cobertura. Pesquisa Agropecuária Tropical, Goiânia, v.39, p.124-133, 2009.

VENTUROSO, L. R.; RANGEL, M. A. S.; SOUZA, F. R.; BERGAMIN, A. C.; CONUS, L. A.; COLETA, Q. P. Influência de diferentes classes de infestação por mancha púrpura sobre o vigor de sementes de soja. Revista Brasileira de Oleaginosas e Fibrosas, Campina Grande, v.12, n.1, p.41-48, 2008.

WRATHER, J. A.; KOENNING, S. R. Effects of diseases on soybean yields in the United States 1996 to 2007. Plant Health Progress, Saint Paul, v.10, n.1, p. 1-7, 2009. 